\title{
Teoria da instrução como cultivo social do espírito humano: papel formativo do interesse e da disciplina em John Dewey
}

\author{
Theory of instruction as social cultivation of the human mind: \\ formative role of interest and discipline in John Dewey
}

Claudio Almir Dalbosco*

Ao professor Jürgen Oelkers, em reconhecimento à sua nova e profunda interpretação do pensamento pedagógico de John Dewey.

\section{Resumo}

O ensaio investiga aspectos da teoria educacional de John Dewey, tomando como referência textual o capítulo X de Democracy and Education. Procura mostrar a profunda influência que o pedagogo americano sofre da tradição filosófica passada e, simultaneamente, sua extraordinária capacidade de ir além de tal tradição. Trata, na primeira parte, de sua nova noção de Mind (Geist), resultante de sua crítica ao modelo idealista, deixando claro o conflito entre, por um lado, o espírito como entidade mental isolada e independente da experiência humana e, por outro, como ação mediada simbolicamente, cujo sentido brota da condição social da linguagem humana. Na segunda parte, mostra que a condição ativa e participante do espírito permite a Dewey conceber sua teoria da educação como teoria da instrução, interpretando-a no sentido de preparação do ser humano para assumir formas democráticas de vida. É nesse contexto que ele atribui papel indispensável tanto ao interesse como à disciplina. $O$ ensaio procura mostrar, em síntese, que a teoria da instrução ancorada nas noções de interesse e disciplina torna-se referência moral indispensável para Dewey pensar a democracia como forma de vida e organização social.

Palavras-chave: Ação. Democracia. Disciplina. Espírito. Instrução. Interesse.

\section{Abstract}

This essay examines aspects of John Dewey's educational theory, taking chapter X of Democracy and Education as reference. It seeks to show the profound influence that the American pedagogue suffers from the past philosophical tradition and, at the same time, his extraordinary capacity to go beyond such tradition. In the first part, it addresses his new notion of Mind (Geist), which results from his critique of the idealist model, making clear the conflict between, on the one hand, the spirit as an isolated mental entity that is independent of human experience and, on the other hand, as symbolically mediated action, whose meaning springs from the social condition of the human language. In the second part, it shows that the active and participatory condition of the spirit allows Dewey to conceive his theory of education as a theory of instruction, interpreting it in the sense of preparing the human being to assume democratic forms of life. In this context, he assigns an indispensable role to both interest and discipline. In summary, the essay seeks to show that the theory of instruction underpinned by the notions of interest and discipline becomes an indispensable moral reference for Dewey to think of democracy as a way of life and social organization.

Keywords: Action. Democracy. Discipline. Instruction. Interest. Mind.

Recebido em 09/07/2017 - Aprovado em 03/12/2017

http://dx.doi.org/10.5335/rep.v25i1.8031

* Doutor em Filosofia pela Universidade de Kassel (Alemanha). Professor Titular do Programa de Pós-Graduação em Educação da Universidade de Passo Fundo e bolsista de produtividade em pesquisa do Conselho Nacional de Desenvolvimento Científico e Tecnológico (CNPq).E-mail: vcdalbosco@hotmail.com 


\section{Introdução}

Prestar tributo a um clássico, dialogando com seu pensamento, é desafio árduo, considerando a profundidade de ideias que seu texto geralmente contém. Democracy and Education (Democracia e Educação) (2008), de John Dewey (18591952), é uma destas obras que sempre aprendemos algo de novo ao revisitá-las, dada sua riqueza de pensamentos. Dewey empreende diálogo vivo com a tradição pedagógica clássica, com grandes autores, como John Locke (1632-1704), Jean-Jacques Rousseau (1712-1778), Immanuel Kant (1724-1804) e Johann Friedrich Herbart (1776-1841), para citar apenas alguns dos modernos mais expressivos, inovando a teoria educacional sob vários aspectos. $\mathrm{O}$ modo como interpreta criativamente a tradição pedagógica clássica, buscando atualizá-la, torna-se exercício formativo de alto nível tanto para a filosofia da educação como, especialmente, para a ampla pesquisa educacional. Nesse aspecto, Democracy and Education, passados já mais de cem anos de sua primeira publicação, continua sendo fonte de inspiração às novas gerações, sobretudo, porque mostra como a educação, além de poder ser tema inesgotável de investigação, também é fonte de transformação humana e social. Na leitura dessa obra, aprendemos muito sobre complexidade, multiplicidade e indispensabilidade do fenômeno educativo à vida humano-social. Dewey, como poucos, tocou fundo na condição humana, evidenciando o quanto o problema da formação humana é indispensável para a democracia como forma de vida e organização social.

Considerando a grandeza de Democracy and Education, fazer um recorte para homenagear seu centenário não é tarefa fácil. Eu tenho revisitado esta obra com certa regularidade desde minha graduação e tenho-o feito nos últimos dois anos ainda com maior frequência, devido ao meu blog semanal, ${ }^{1}$ no qual procuro comentá-la passo a passo, quase parágrafo por parágrafo. Da ampla diversidade temática que aparece na obra, gostaria de me concentrar especificamente, neste ensaio, no problema do cultivo do espírito humano, considerando o modo como é tratado no capítulo X de Democracy and Education. Penso que a interpretação desse problema conduz ao coração da própria teoria deweyana de educação, pois, nesse capítulo, além de Dewey tratar de noções pedagógicas capitais, como interesse e disciplina, também instrui formativamente o leitor sobre seu próprio modo de dialogar com a tradição pedagógica clássica. ${ }^{2}$ Aprendemos muito com a leitura da referida obra, sobre como é possível compreender crítica e criativamente a tradição intelectual passada e como, ao fazer isso, preparamo-nos melhor conceitualmente para compreendermos nossa própria atualidade. 
A reconstrução que empreendo neste ensaio está diretamente relacionada aos meus próprios interesses investigativos no âmbito da filosofia da educação, auxiliando-me, por isso, a melhor esclarecê-los. Tenho perseguido, no meu atual projeto de pesquisa, ${ }^{3}$ o problema da formação humana como exercício de si, em autores como Lúcio Aneu Sêneca (4 a. C. - 65 d. C), Jean-Jacques Rousseau e Johann Friedrich Herbart, deixando-me inspirar pela obra A hermenêutica do sujeito, de Michel Foucault (1926-1984). Considerando isso, formulo a hipótese, no presente ensaio, tomando em específico o capítulo X de Democracy and Education, que Dewey chega à noção crucial de educação como cultivo social do espírito humano porque conhece bem a tradição pedagógica clássica, deixando-se inspirar pela ampla tradição da Bildung alemã, ${ }^{4}$ especialmente pelas ideias pedagógicas de Herbart. É com base em tal inspiração que ele pode conceber o interesse humano como mola propulsora da ação humana em geral e da ação pedagógica em especial. É igualmente pela influência da moderna tradição da Bildung, representada especialmente na versão herbartiana neo-humanista, que Dewey pode atribuir papel formativo à disciplina, concebendo-a como modo principal de cultivo e, portanto, de exercício de formação social do espírito humano. Além da tradição neo-humanista alemã, também é, certamente, pela influência da tradição pragmatista americana, principalmente de Georg Herbert Mead (1863-1931), que ele critica pontualmente a noção idealista de espírito.

Para dar conta de tal hipótese, desdobro minhas reflexões em duas partes. $\mathrm{Na}$ primeira, reconstruo a crítica deweyana do modelo idealista de espírito humano, para expor, em seguida, o próprio sentido que o pedagogo americano lhe atribui. A crítica ao modelo idealista de espírito, inspirada em parte pela tradição moderna da Bildung, permite pensá-lo como grande capacidade humana executiva, que, mobilizando as outras capacidades, coloca-se a serviço da ampla formação cultural. Na segunda parte, investigo o nexo entre teoria da instrução e papel formativo do interesse e da disciplina, chegando à conclusão de que a democracia como forma de vida depende do espírito armado culturalmente. Isso pode ter resultado prático (moral-formativo) atual de grande alcance, fortalecendo a convicção de que a formação cultural, ampla e consistente, ainda continua sendo a melhor arma contra as formas de vida individualistas e autoritárias que, cada vez mais, tomam conta da sociedade contemporânea.

\section{A noção de espírito: do imobilismo à condição humana ativa e participante}

A noção de espírito humano é central para a tradição pedagógica moderna, especialmente a alemã. Entre os próprios pensadores alemães, essa terminologia não é de modo algum clara e consensual. Geist (espírito) talvez seja a expressão fi- 
losófica mais significativa, mas Bewusstsein (consciência), além de estar associada ao espírito, também é amplamente empregada. A filosofia moderna, em sua versão francesa, cartesiana, começa com o problema da consciência e não com o espírito. Immanuel Kant, depois de René Descartes (1596-1650), continua, até certo ponto, adotando a noção de consciência, transformando o cogito na estrutura transcendental do eu penso para justificar o emprego teórico da razão pura. ${ }^{5}$ Somente mais tarde, com Georg W. F. Hegel (1770-1831), é que a noção de espírito fará notadamente fortuna teórica, consolidando-se, do ponto de vista filosófico, como noção metafísica chave e, do ponto de vista pedagógico, como base da teoria idealista da educação.

John Dewey, partindo do significado da moderna noção de espírito, oferece-lhe sentido inteiramente novo. No entanto, o amplo e profundo emprego, tanto filosófico como pedagógico, que é dado em Democracy and Education à expressão Mind não se refere simplesmente à tradução inglesa direta da noção filosófica alemã Geist. De outra parte, Mind não pode ser interpretada só de acordo com os cânones atuais da filosofia da mente e, por isso, também não deve ser traduzida para o português apenas como mente. ${ }^{6}$ Ou seja, preservar na tradução portuguesa a noção de espírito é decisivo: por um lado, para evitar o possível reducionismo das questões filosóficas de Democracy and Education a problemas de filosofia da mente; por outro, para manter o rigor daquele sentido que Dewey atribui à filosofia da educação, cuja fonte de seus problemas jorra da moderna filosofia da educação continental. Tais são, tipicamente, como deixarei claro adiante, as noções de interesse e disciplina, que só adquirem sentido formativo quando compreendidas, especialmente, por meio da influência da moderna tradição da Bildung.

Para compreender a transformação que Dewey faz do conceito de espírito, atribuindo-lhe nova significação, faz-se necessário considerar a influência filosófica decisiva da tradição pragmatista americana, especialmente de seu amigo pessoal e colega profissional na Universidade de Chicago, Georg Herbert Mead. A noção de ação humana mediada simbolicamente, desenvolvida por Mead, permite a Dewey aprofundar o dinamismo simbólico-social que está na base de formação do espírito humano. Do ponto de vista especificamente pedagógico, Mead influenciou Dewey na compreensão da formação linguística do Self, auxiliando-o também para pensar a ação educativa como ação mediada simbolicamente. ${ }^{7}$ Da noção de ação humana como interação mediada simbolicamente, resulta a compreensão da interação pedagógica entre professor e aluno como relação intersubjetiva mediada pelo aspecto significante do símbolo linguístico. ${ }^{8}$ Com isso, pode-se perceber o quanto a linguagem, cuja significação simbólica é construída socialmente, desempenha papel importante na teoria educacional de Democracy and Education. 
No capítulo X da referida obra, Dewey procede de maneira negativa para expor sua nova noção de espírito, mostrando inicialmente o modo como tal noção não deve ser compreendida. Dessa forma, a concepção idealista de espírito representa exatamente aquele modo a ser recusado, sobretudo, por assumir o princípio filosófico básico de colocar o espírito acima do mundo das coisas e dos fatos que se pretende conhecer. A versão mais simples e abrangente do idealismo defende que as ideias só possuem sentido na medida em que se mantiverem independentes dos objetos do mundo e dos próprios acontecimentos humanos. As ideias são forças poderosas exteriores ao mundo, que, movidas pelo espírito, dinamizam o mundo, dando-lhe sentido. Em síntese, do ponto de vista filosófico, o pensamento idealista baseia-se na crença sobre a existência de um princípio último, colocando em sua base a própria noção de ideia. Ou seja, a ideia é o princípio último a partir do qual se deduz tudo o mais.

Essa compreensão filosófica geral do espírito humano tem muitas implicações, tanto cognitivas, no sentido epistemológico mais amplo, como educativas, em sentido estritamente pedagógico. Primeiramente, no sentido epistemológico, o conhecimento é compreendido como aplicação externa de entidades mentais (ideias) às coisas a serem conhecidas. Nessa perspectiva, conhecimento é um ato puramente intelectivo, movido por ideias, que determina verticalmente a experiência sensível por meio do olhar externo e superior a ela. Nesse contexto, o espírito se autoconcebe nos moldes da imagem especular que, refletindo-se a si mesma, domina, subsumindo, tudo o que está a sua volta. Por proceder assim, o espírito especulativo torna-se incapaz de compreender o aspecto vivo e dinâmico da própria experiência humana. Essa maneira de pensar tem obviamente profundos desdobramentos educacionais, que são inclusive ignorados por teorias educacionais atuais, especialmente alemãs, que ainda mantêm traços idealistas fortes.

Jürgen Oelkers esclarece, no posfácio que escreve à tradução alemã de Democracy and Education, o quanto o pensamento de John Dewey tornou-se objeto de equívoco no cenário pedagógico alemão, desde a Reforma Pedagógica até os dias atuais. Isso se deve, em parte, segundo ele, ao modo como a tradição filosófica pragmatista foi interpretada por pedagogos como Eduardo Spranger e Georg Kerschensteiner, que recebiam forte influência da tradição do idealismo alemão e de seu conceito especulativo de espírito. Nas palavras de Oelkers: "Desde então John Dewey tornou-se na Alemanha um marginal man, de certo modo conhecido, sobretudo mediante os clichês dos pedagogos da Reforma e, raramente lido, mas apenas traduzido, permaneceu pouco recebido até o fim do século XX" (OELKERS, 2010, p. 491-492). Isso fez com que o próprio Oelkers tomasse para si a responsabilidade 
de reintroduzir John Dewey no cenário intelectual alemão, escrevendo uma obra de peso, na qual oferece nova e profunda interpretação do pensamento de Dewey. ${ }^{9}$

Para o que interessa no momento, a interpretação idealista do espírito faz com que, do ponto de vista educativo, a matéria de estudo, ou seja, o conteúdo que constitui as mais diferentes disciplinas, como história, biologia e física, seja transformada em ideias. A mesma superioridade filosófica que as ideias possuem em relação ao mundo, que a atividade especulativa do espírito tem em relação à experiência sensível, traduz-se na superioridade da matéria do ensino em relação ao próprio sujeito educacional. O fetiche parece tornar-se claro: a matéria, que é o objeto do ensino, transforma-se em sujeito, e o próprio sujeito educacional é reduzido à condição de instrumento, ou seja, à mera coisa. Sendo assim, no âmbito da educação idealista, a matéria de ensino assume misteriosamente o lugar do sujeito, para que possa ser ditada pelo professor e memorizada pelo aluno. A partir disso, compreende-se também a proeminência que o manual de ensino assume no âmbito das teorias educacionais de matriz escolástica.

A transformação em fetiche da matéria de ensino gera grande efeito destrutivo à formação humana, exemplificando-se concretamente na relação pedagógica entre professor e aluno. Desse modo, a tarefa do professor é precisamente transformar o conteúdo de sua disciplina em ideia, ou seja, em entidade mental isolada, e transmiti-la ao aluno, o qual, por sua vez, deve assimilá-la de maneira passiva. A transformação do conteúdo em entidade mental isolada, tornando-a distante da experiência de mundo do aluno, é o que possibilita o processo educativo baseado no mecanismo transmissão-memorização. Contudo, é justamente tal transformação, apoiada meramente no uso formal e repetitivo do manual, que faz do próprio ensino algo pesado e maçante, inteiramente desinteressante ao aluno. Tornar o ensino interessante ao aluno já se constituía na primeira preocupação pedagógica herbartiana, sendo, então, assumida e reatualizada por Democracy and Education. Desse modo, a mesma crítica que Herbart fará à pedagogia escolástica na Alemanha do século XIX Dewey fará nos Estados Unidos, no início do século XX, considerando o contexto educacional específico, no qual a pedagogia de tradição europeia é inserida.

Este é, então, resumidamente, o núcleo do modelo idealista de educação. Com ele se ignora - e este é o limite mais expressivo de tal concepção - a noção de educação como crescimento (growth), ou seja, como aperfeiçoamento contínuo da própria experiência humana, que se dá na e pela experiência. O mecanismo transmissão-assimilação, por se basear na lógica do observador distante,$^{10}$ que transforma a matéria de ensino em entidade mental isolada, impede professor e aluno de se colocarem como sujeitos ativos na situação pedagógica e se conceberem interagin- 
do simbolicamente, como sujeitos que precisam do reconhecimento intersubjetivo para crescer como humanos. Em síntese, educação como crescimento pressupõe a noção de espírito ativo e participante, baseado na plasticidade da condição humana. Contudo, a concepção de espírito ativo e participante exige nova concepção antropológica, que o modelo idealista é incapaz de oferecer. Tal antropologia lança suas raízes na noção pragmatista de condição humana e em sua respectiva teoria da ação. ${ }^{11}$

Este motivo filosófico, de base nitidamente antropológica, leva Dewey a se opor criticamente ao modelo idealista. Segundo ele, "os fatos do interesse" (the facts of interest) mostram o misticismo e o caráter equivocado de tal modelo filosófico-educacional. Em que sentido? Sua crítica torna-se possível, primeiramente, porque o próprio Dewey compreende o espírito de outra maneira, inteiramente diferente em relação ao jargão idealista. Assim destaca ele, em uma passagem esclarecedora de Democracy and Education: "O espírito (Mind) ${ }^{12}$ aparece na experiência (experience) como capacidade para responder aos estímulos presentes sobre a base de antecipação das futuras consequências possíveis, com o propósito de controlá-las" (DEWEY, 2008, p. 137, tradução nossa). Vários aspectos desta passagem precisam ser interpretados à luz do problema deste meu ensaio, a saber, do cultivo social do espírito humano por meio do interesse e da disciplina, considerados como núcleo da própria formação humana.

O primeiro aspecto a ser considerado é o vínculo estreito entre espírito e experiência. A experiência certamente é uma das noções filosóficas mais genuínas do pensamento de Dewey, e não há dúvida que é por meio dela que o pensador americano se distancia do modelo idealista de espírito. Embora Dewey não esclareça devidamente o sentido dessas duas expressões, o leitor pode supor, ao menos, que 0 espírito é uma expressão mais ampla, que engloba todas as capacidades humanas, tornando-se a fonte da qual elas brotam. Já a experiência, por seu turno, é o amplo exercício humano que habilita o próprio espírito a se transformar em capacidade. Mais precisamente, é pela experiência que o espírito se deixa transformar em capacidade prática tanto no sentido executivo como estritamente moral. Portanto, a ampla experiência humana torna-se uma espécie de órgão executivo do espírito, transformando-o em capacidade ativa e participante.

Ora, nisto reside o núcleo da crítica ao modelo idealista: o espírito, transformando-se em capacidade, responde aos estímulos que o sujeito sofre por meio de sua interação com o ambiente, com os outros seres humanos e consigo mesmo. Para poder responder a tais estímulos, o espírito vê-se obrigado a se transformar em uma capacidade executiva, deixando de ser entidade mental isolada, meramente especulativa. É como capacidade executiva que ele pode, então, empreender duplo 
exercício, indispensável à coordenação da ação humana, a saber, de antecipação e, por conseguinte, de maior controle das consequências resultantes do plano de ação. A capacidade executiva habilita o espírito a ampliar o âmbito de visão sobre acontecimentos futuros, preparando-o da melhor forma possível para dominar os resultados de sua própria ação. Prever as possíveis consequências de sua ação e poder antecipar-se a elas são possibilidades da condição humana que, por não ser inata, precisa ser formada. Neste ponto reside, em parte, o papel principal da educação: cultivar, por meio de diferentes exercícios, o espírito humano, transformando-o em comitê executivo das diferentes capacidades humanas.

Em outra passagem, Dewey define o espírito da seguinte maneira: "Esta previsão e esta inspeção com referência ao que se prevê constituem o espírito. A ação que não implica tal antecipação dos resultados e tal exame dos meios e dos obstáculos torna-se objeto de hábito ou simplesmente significa uma ação cega" (DEWEY, 2008, p. 138, tradução nossa). Confirma-se, novamente, a definição de espírito como capacidade humana de previsão e exame do que se prevê. Isso exige dele, imediatamente, a capacidade agente, pois prever e examinar são exercícios de refinamento do espírito que só podem acontecer adequadamente na experiência e, portanto, só se dão no âmbito da ação humana. O espírito especulativo, que se distancia excessivamente da realidade, mantendo-se em um mundo abstrato, alheio à experiência, é incapaz de preparar o sujeito para o modo de vida democrático, o qual exige dele interação ativa e participante. Exige dele, portanto, um nível de sociabilidade que a concepção idealista, dados seu isolamento e sua especulação, não consegue dar.

Em síntese, a nova noção de espírito exige seu vínculo direto com a experiência humana, transformando-o em centro irradiador das diversas capacidades humanas. Mas, a noção deweyana de espírito não se esgota nisso, pois, se Dewey concebesse o cultivo do espírito somente em sua relação com a experiência humana individual, ele permaneceria tão somente nos trilhos da tradição pedagógica moderna. Buscando ir além de tal tradição, Dewey lhe atribui a caraterística central da interação social, concebendo-o como interação mediada simbolicamente. Assim se expressa o pedagogo americano: "O ato do ser humano pode ser individual no curso inicial de alguns acontecimentos, porém o resultado depende da interação de sua resposta com as energias oferecidas por outros agentes" (DEWEY, 2008, p. 139, tradução nossa). O ser humano inicia a ação, mas os passos seguintes só acontecem porque há a interação dele com outros seres humanos e com o amplo ambiente. Ora, este conteúdo interativo-social do espírito, mediado simbolicamente, é que permite a compreensão da educação como fenômeno eminentemente social. ${ }^{13} \mathrm{Como}$ esta dimensão social não é inata, mas precisa ser formada, então, o interesse e a disciplina tornam-se as duas principais forças pedagógicas dessa formação. 
Gostaria de resumir o principal resultado da investigação empreendida até este momento: o espírito humano, quando vinculado à experiência, transforma-se em força dinamizadora das capacidades humanas, assumindo ele próprio a forma de uma capacidade executiva, que torna possível a previsão e o controle das consequências que emergem da ação humana. Este dinamismo ativo e participante do espírito diferencia-se profundamente daquele caráter especulativo e isolado, próprio ao modelo idealista. Como são o interesse e a disciplina que impulsionam e orientam o espírito, tornando-o ativo e participante, faz-se necessário investigar o sentido formativo que Dewey lhes atribui. Contudo, como tal sentido insere-se em sua teoria mais ampla da instrução, preciso iniciar com sua exposição.

\section{Educação como instrução: papel formativo do interesse e da disciplina}

Opondo-se ao modelo idealista de educação, Dewey pensa o cultivo do espírito humano de maneira pragmatista. Concebe-o como capacidade humana social, ativa e participante, atribuindo-lhe papel executivo indispensável para tornar inteligente a ação humana. Nesse contexto, são o interesse e a disciplina que dão sentido formativo à capacidade do espírito, e só conseguem fazê-lo - esta é minha hipótese $\square$ porque estão ancorados na noção de instrução que se diferencia fortemente do modelo idealista. Considerando isso, preciso iniciar a exposição deste tópico referindo alguns aspectos da nova teoria deweyana da instrução. Pelo fato de Dewey levar tão a sério seu diálogo vivo com a tradição, a novidade de sua teoria da instrução preserva, como esclareço logo a seguir, algo fundamental do próprio sentido greco-romano de instrução.

\section{Educação como instrução (instruction)}

Está correto considerar a teoria da educação de Dewey como teoria da instrução (theory of instruction), desde que se compreenda adequadamente a própria noção de instrução. Tal noção é muito empregada pelo autor ao longo de Democracy and Education, sendo que é especialmente no capítulo $\mathrm{X}$ da referida obra que ocorre textualmente a identificação entre educação e instrução. Considerando isso, a instrução não pode ser reduzida, obviamente, apenas ao preparo de um ofício (profissão) e, menos ainda, ao manuseio de técnicas de ensino. Para, por um lado, poder distanciar-se da formalização escolástica de ensino predominante em sua época e, por outro, aprofundar o nexo entre democracia e educação, o esforço teórico de Dewey irriga-se de seu profundo conhecimento da tradição pedagógica passada, incluindo a longínqua tradição greco-romana. A irrigação é tal que o per- 
mite inclusive atribuir papel formativo ao cultivo do espírito humano e pensá-lo de maneira abrangente.

Desse modo, Dewey coloca o problema da instrução (the problem of instruction) na base de suas ideias filosófico-pedagógicas principais, como da condição ativa e participante do espírito humano, da dimensão social do processo formativo e do respeito pelos interesses dos alunos. Na história da pedagogia, desde a Antiguidade até nossos dias, a instrução sempre foi tomada como noção importante das teorias educacionais. Tanto na versão da parauskeué grega como da instructio latina, instrução tem a ver com a preparação, mas não exclusivamente para o trabalho, no sentido de apenas ensinar determinada profissão ao aluno. Preparação tem o sentido mais amplo de cultivo do espírito humano para enfrentar as intempéries da vida. É assim que o espírito cultivado em todas as suas capacidades este é o grande ideal greco-latino de educação - torna-se fortalecido para enfrentar a grande tragédia que são a condição humana e sua vulnerabilidade frente aos acontecimentos do mundo. Pois, sem o espírito fortalecido, o ser humano não seria capaz de suportar o peso da existência, sucumbindo diante da fragilidade de sua própria condição. Por isso a importância atribuída pela tradição pedagógica antiga à noção de instrução como preparação, estendendo-a ao longo da vida do ser humano, não limitando-a somente ao período escolar, uma vez que a compreende como processo indeterminado, que acontece, na experiência humana, sempre de maneira inconclusa.

A teoria educacional de Dewey é profundamente tributária de tal tradição, e, por isso, the problem of instruction significa, para ele, antes de tudo, preparação para a vida em sentido amplo. Significa, especificamente, do ponto de vista ético-político, o preparo do ser humano para assumir a democracia como modo de vida, e, para isso, ele precisa ter seu espírito cultivado em todas as suas capacidades, incluindo, entre elas, a simpatia inteligente (intelligent sympathy), ${ }^{14}$ a qual Dewey coloca na base da postura humana solidária e cooperativa. No entanto, o problema da instrução ganha ainda maior especificidade pedagógica quando se refere, no âmbito da educação escolar, ao modo de encontrar materiais que introduzam o aluno em atividades específicas, tornando-as interessantes para ele. Por isso, tal modo precisa tratar as coisas e os meios pedagógicos como condições para a execução das próprias finalidades pedagógicas.

Se a instrução é preparação do espírito do educando por meio de atividades específicas, e se tais atividades são movimentadas pelo manuseio que ele faz de determinados materiais, então, torna-se nuclear à noção pragmatista deweyana de instrução a escolha adequada de tais materiais. Nesse contexto, são os interesses do próprio aluno que se tornam critério decisivo para tal escolha. A instrução sig- 
nifica, desse modo, no âmbito da educação escolar, o esforço pedagógico de tornar ativo o próprio aluno por meio de materiais que lhe são interessantes. Contudo, o aluno torna-se ativo e participante - e este é o credo pedagógico deweyano mais elementar - quando ele tem a oportunidade de pôr em jogo, no processo de instrução, seus próprios interesses. Somente assim, ou seja, só quando seus próprios interesses são levados em conta, tanto pela escola como pelo professor, é que a matéria de ensino pode se tornar atrativa para ele. Mas isso não significa que o professor e a escola tenham que aderir integralmente aos interesses do aluno. É um aspecto nuclear da ideia de educação como crescimento que escola e professor precisam redimensionar os interesses dos alunos, considerando a finalidade mais ampla da própria instrução.

Desse modo, compreender de maneira inteiramente nova o espírito humano e buscar novas formas pedagógicas de cultivá-lo são duas exigências centrais da nova teoria da instrução. Em vez de pronto e completo em si mesmo, o espírito é, como vimos anteriormente, algo profundamente indeterminado; mas, por seu próprio dinamismo ativo e participante, ele está sempre a caminho, na companhia interativa de outros e do amplo ambiente, da incansável busca por seu aperfeiçoamento. ${ }^{15}$ Movido por interesses, deixa-se cultivar por diferentes modos de exercício, os quais assumem, no âmbito da educação escolar, a forma paradigmática da disciplina. Vê-se, com isso, o quanto interesse e disciplina oferecem oportunidades pedagógicas reais para que o espírito humano, rompendo com seu isolamento, cultive a si mesmo na permanente companhia interativa com o ambiente. Na terminologia deweyana, interesse e disciplina são modos pedagógicos cruciais de formação social do Self.

\section{Papel formativo do interesse e da disciplina}

A instrução como cultivo social do espírito humano depende do papel formativo tanto do interesse como da disciplina. Cabe investigar, brevemente, nas páginas que seguem, como Dewey justifica isso no capítulo $\mathrm{X}$ de Democracy and Education. Se a noção greco-romana de instrução como preparação influencia sua concepção de instruction, no que se refere especificamente ao interesse e à disciplina, a influência da pedagogia moderna, especialmente do neo-humanismo de Johann F. Herbart, ${ }^{16}$ se faz sentir em sua inteireza. Sem levar em consideração tal influência, dificilmente se compreende o papel formativo que Dewey atribui tanto ao interesse como à disciplina. 


\section{0 interesse}

Em seu clássico livro sobre a pedagogia de Johann F. Herbart, Dietrich Benner (1993, p. 98) enfatiza o aspecto não psicologista da noção de interesse, evitando que seja reduzido simplesmente ao estado emotivo do sujeito educacional. Considerando isso, o interesse significa, filosoficamente, a intencionalidade específica da ação de tal sujeito, designando sua atividade intelectual de apropriação do mundo e de sua própria autorreflexão. Ele representa, do ponto de vista formal, o movimento do espírito duplamente constituído pelo aprofundamento e pela reflexão. Nesse sentido, o interesse significa, então, a capacidade intelectual mais ampla, que contém em si a possibilidade de outras capacidades humanas. Do ponto de vista material, o interesse refere-se aos estados de espírito do conhecimento e da simpatia, sendo que Herbart atribui sentido empírico, especulativo e estético ao primeiro e à simpatia, o sentido participativo, social e religioso. Como conceito intelectual pedagógico e não psicológico, o interesse, quando vinculado à multiplicidade, tem grande alcance formativo, sintetizado pela própria noção de interesse pedagógico. ${ }^{17}$

Outro aspecto importante da "teoria do interesse" de Herbart é que ele a vincula à ideia de educação geral, compreendida como formação múltipla (vielfältige Bildung). Não custa lembrar, nesse sentido, que Herbart atribui à sua obra Allgemeine Pädagogik (Pedagogia geral) (1965) o subtítulo "Derivada da finalidade da educação", que é lamentavelmente excluído da tradução portuguesa (HERBART, 2003). Sua ideia é justamente inserir a noção de interesse, como também fará com a de disciplina, na ideia de educação geral (allgemeine Erziehung), que, por sua vez, também deita fortes raízes na tradição greco-romana da instrução como preparação. Desse modo, sua Pedagogia geral, alicerçada na ideia de educação geral, bebe na fonte tanto da Paideia grega como da Humanitas latina, apresentando o objetivo de desenvolver, de maneira integral e equilibrada, todas as capacidades humanas em todas as direções.

Como bom conhecedor do pensamento pedagógico de Herbart, Dewey deixa-se influenciar por sua noção de interesse ${ }^{18}$ reinterpretando-a de acordo com sua concepção de espírito e inserindo-a em sua teoria pragmatista da educação. Mas em que sentido a teoria herbartiana do interesse o influencia? Ele retém dela a noção de interesse como impulso ético à ação, para colocá-la na base de sua ideia de participação como aspecto constitutivo da condição humana. Ou seja, são interesses que levam o ser humano a tomar parte da vida social, e isso ocorre na mesma medida em que os próprios interesses humanos formam-se pela convivência social. Ora, é a condição humana participante interessada que está na base da formação social do Self e, por conseguinte, da democracia como forma de vida. 
Para esclarecer a noção de interesse, Dewey toma como referência, no capítulo $\mathrm{X}$ de Democracy and Education, duas atitudes humanas diferentes, a atitude do mero espectador, que olha de fora e de maneira distanciada os acontecimentos, e a atitude do participante, que desde o início está envolvido com o que acontece (DEWEY, 2008, p. 139). Ele expõe a atitude do observador distante e desinteressado, tomando como exemplo o prisioneiro que olha a chuva pela janela de sua cela: tudo é igual para ele, mantendo-se completamente indiferente ao acontecimento. Manter-se indiferente ao que acontece talvez seja a postura mais fria do ser humano, pois, por não sentir emoção, torna-se incapaz de se entregar ao acontecimento. Sem emoção e entrega, não há sentimento ético, e, nesse contexto, o outro ser humano não lhe faz a menor diferença. Ao assumir a condição de indiferença, o ser humano decai, embrutecendo seu modo de vida.

A postura do participante é oposta à do observador distante. Buscando ligar-se profundamente ao que acontece, faz de tudo para influenciar a direção dos acontecimentos. Portanto, querer mudar o curso dos acontecimentos e de sua própria vida é uma característica básica do observador participante. Ele se preocupa com as coisas, envolve-se com os acontecimentos e, com isso, transforma a si mesmo e aos outros. Como o próprio Dewey afirma, a atitude do participante caracteriza-se duplamente: pela solicitude e pela ansiedade atenta, proporcionando-lhe a condição de poder antecipar-se minimamente aos acontecimentos. Sua própria condição de participante - e este é o aspecto decisivo - só é possível na medida em que ativa a capacidade de abertura aos outros, interagindo simbolicamente com eles.

Cabe notar ainda que, em sua reflexão sobre o interesse, Dewey emprega a expressão afecção, que define tanto a condição humana como aquilo que é próprio da educação. Desse modo, interesse é o estado humano afetado que impede o ser humano de se tornar indiferente às coisas, aos outros e a ele mesmo. Se olharmos mais de perto, estar afetado é o impulso inicial que impele o ser humano para a educação. Ele se sente incompleto, vê que lhe falta algo e dirige-se ao que está a sua volta para buscar completar-se naquilo que lhe falta. Esta força de dirigir-se ao outro, buscando constantemente se aperfeiçoar respeitando o outro e a si mesmo, é o sentido ético do interesse como afetação que o torna mola propulsora do cultivo social do espírito humano.

$\mathrm{Na}$ sequência, depois de ter esclarecido as duas atitudes humanas mais usuais, a do observador distante e a do participante, Dewey insere-as em sua tese filosófico-pedagógica de fundo: tudo o que o sujeito é ou deixa de ser depende de sua interação com o ambiente. Portanto, ninguém se forma sozinho, isolado. Como ele afirma: "As atividades da vida florescem e fracassam só em conexão com as mudanças do ambiente" (DEWEY, 2008, p. 140, tradução nossa). Disso decorre, do 
ponto de vista filosófico, que a realização humana depende da boa relação que 0 ser humano estabelece com o ambiente. $O$ fracasso resulta da conexão precipitada, feita de maneira errada; evitar tal tipo de conexão coloca-se como exigência para o modo de vida voltado à felicidade.

Que ideia de interesse resulta da tese deweyana de que o sujeito constrói-se a partir de sua interação com o ambiente? No contexto de sua filosofia social, Dewey define interesse como marca do comprometimento recíproco entre o si mesmo (Self) e o mundo, pois é justamente esse comprometimento que torna possível a formação do sujeito. Por exemplo, se lhe houvesse um mundo exterior extremamente agressivo, ele seria imediatamente destruído. É o caso da revolta da natureza: tempestade, fogo, frio e seca provocam destruição dos organismos vivos e, por conseguinte, também da vida humana. Porém, quando a natureza conspira a favor da vida, o ser humano floresce, e há o ambiente propício à cultura e, com ela, à própria educação. O emprego da expressão "comprometimento recíproco" mostra certo otimismo de Dewey, no sentido de que há disposição do sujeito e condições do ambiente para o encontro construtivo. É precisamente nesse sentido que a própria formação humana depende da interação mínima do sujeito educacional com o ambiente. Contudo, condições ambientais podem se tornar favoráveis à formação humana desde que os seres humanos saibam aproveitá-las adequadamente.

Em síntese, Dewey faz uma introdução geral da noção de interesse nos parágrafos iniciais do capítulo $\mathrm{X}$ de Democracy and Education, que se deixam resumir em dois aspectos principais: a) o interesse está associado primeiramente à condição ativa do sujeito, tornando-o um ser participante; b) o interesse constitui a interação recíproca entre sujeito e ambiente. Portanto, por ser sujeito ativo e por interagir constantemente com o mundo, o ser humano tem a possibilidade de se educar, porque as coisas lhe afetam de alguma maneira. Na condição de sujeito participante, o ser humano deixa para trás a indiferença e o isolamento, sentindo-se envolvido pelos acontecimentos e pelo próprio calor humano.

Esses aspectos preparam a exposição do sentido especificamente pedagógico de interesse, que ocorre na sequência do capítulo X de Democracy and Education. Em que repousa propriamente tal sentido? Dewey coloca o interesse, do ponto de vista pedagógico, como elo entre o desenvolvimento das capacidades humanas específicas e os objetos de ação que provocam tal desenvolvimento. Como a formação humana implica atividades, e como estas são impulsionadas por objetos de ação, o interesse representa a síntese entre ambos: por meio de objetos de ação, o interesse mobiliza atividades visando ao desenvolvimento das próprias capacidades humanas. O que está em jogo, como se pode observar, é o desenvolvimento das capacidades humanas. Sem a condição humana, social e ativa, tais capacidades 
não se desenvolvem, sendo o interesse, nesse sentido, a condição social ativa por excelência. Por isso, o interesse simboliza pedagogicamente o esforço empreendido pelo ser humano para colocar em movimento suas próprias capacidades, e ele só consegue fazê-lo porque age interativamente.

Dewey procura dar concretude para este sentido pedagógico geral de interesse, pensando-o no âmbito da relação entre aluno e professor. Busca auxílio na própria etimologia da palavra interesse, definindo-a como aquilo que está entre o que conecta duas coisas distintas, que de outro modo permaneceriam completamente isoladas uma da outra. Ao compreender a educação como crescimento - e este é o núcleo de sua definição de educação -, Dewey concebe um espaço social livre entre o estado imaturo inicial do educando e seu processo de aperfeiçoamento progressivo que deve ser preenchido. No âmbito da instrução, o estado inicial é representado pelas capacidades presentes dos alunos; a finalidade do professor representa o limite remoto. Entre esses dois estados distantes e desconexos entre si, colocam-se várias outras coisas, como os meios educacionais, os atos que precisam ser realizados, as dificuldades que precisam ser vencidas e os procedimentos que precisam ser empregados.

Mas o que o interesse tem a ver com esta maneira pedagógica de pensar? O interesse engloba tudo, desde a posição inicial do aluno, a finalidade e o papel do professor, até os meios a serem empregados. Permeando esses três aspectos do processo formativo, o interesse canaliza a força que impele o aluno a sair de sua condição inicial, exigindo também do professor a escolha de meios pedagógicos adequados para orientar o aluno. No entanto, ao orientarem-se pela dimensão formativa do interesse, professor e aluno precisam estar dispostos a modificar sua própria finalidade pedagógica, tendo de reconstruir seu ponto de vista em respeito aos interesses de cada um. Dewey, assim como Herbart já o havia pensado antes de maneira muito semelhante, insiste na ideia pedagógica de que respeitar os interesses do aluno, tomando-o como ponto de partida do processo pedagógico, não significa manter integralmente tais interesses, sem questioná-los. Ao contrário, a ideia de educação como crescimento implica o esforço pedagógico de elevação dos próprios interesses iniciais do aluno, sendo que o professor e a escola têm papel decisivo nesta tarefa de transformação qualitativa dos interesses do aluno. Nesse sentido, professor e escola só fazem avançá-los na medida em que os põem em questão. Desse modo, por em questão os interesses iniciais que entram em cena na relação pedagógica é uma tarefa irrecusável da educação compreendida como cultivo social do espírito humano.

Em síntese, assim como Herbart, Dewey coloca peso decisivo, em sua teoria da instrução, na noção de interesse, concebendo-o como força social motriz do desen- 
volvimento das capacidades humanas. Pedagogicamente, é o interesse que torna possível a interação simbólica construtiva entre professor e aluno inseridos no amplo ambiente. Para tornar isso ainda mais claro, preciso interpretar, na sequência, como a noção de disciplina se vincula à noção de interesse e em que sentido ela é indispensável à teoria deweyana da instrução.

\section{A disciplina}

O interesse, como vimos, apresenta sentido pedagógico claro, que, vinculado à noção de espírito humano ativo e participante, move o sujeito educacional na direção da instruction. Dessa forma, para Dewey, está claro que sem interesse não há instrução como ampla preparação do ser humano para enfrentar a fragilidade de sua condição e as diversidades do ambiente. Mas qual é o papel da disciplina nesse contexto? É possível afirmar que, no sentido formativo propriamente humano, sem disciplina não há interesse, e sem interesse não há instrução como preparação para o modo de vida democrático. Se a disciplina tem a ver com a democracia, então ela não apresenta apenas sentido negativo. Sendo assim, cabe perguntar: que sentido positivo a disciplina recebe no âmbito do capítulo X de Democracy and Education?

Johann Friedrich Herbart é, novamente, uma das fontes de inspiração de John Dewey. O pedagogo alemão dedica o livro III de sua Pedagogia geral inteiramente para tratar do sentido formativo da disciplina, opondo-o ao sentido negativo que lhe era dado pela pedagogia tradicional. Por desconsiderar os interesses do aluno, não os tomando como ponto de partida do ensino, a pedagogia escolar da época tinha que acentuar o sentido rigoroso e autoritário da disciplina escolar, para poder garantir que a matéria do ensino pudesse ser vencida. Ora, esse sentido autoritário e rigoroso abrangia desde os castigos físicos até o emprego enérgico do manual de ensino, o qual devia ser ditado pelo professor e seguido linha por linha pelo aluno.

Herbart busca atribuir sentido formativo à disciplina, não a compreendendo mais como forma de adestramento (sentido negativo) do sujeito educacional, mas como exercício pedagógico indispensável à formação do autogoverno pedagógico (pädagogische Selbstregierung). Como procurei desenvolver em outro estudo, ${ }^{19}$ Herbart pôde atribuir este sentido formativo à disciplina porque sofreu dupla influência: uma antiga, que remonta a instructio latina, quando concebe a Bildung como forma de transformar o espírito humano em espírito armado - "bewaffneter Geist" (HERBART, 1965, p. 113) - contra a desordem do mundo; e outra moderna, mais precisamente kantiana, quando atribui à disciplina o papel propedêutico inicial de preparar o educando para o exercício moral adulto. ${ }^{20}$ Em qualquer uma dessas duas influências, fica claro para Herbart que a disciplina não pode ser 
adestramento, mas cultivo formativo, isto é, social, das capacidades do educando, visando à formação de seu próprio autogoverno.

Ora, é esse sentido formativo da disciplina que Dewey assume, modificando-o para inseri-lo no âmbito de sua própria teoria da instrução. Que novo significado ele atribui à disciplina? Concebe-a, primeiramente, de maneira ainda muito abstrata, como poder construtivo de realização. Ou seja, nesse sentido, a disciplina é a força maior do espírito que torna inteligente a própria ação humana. Transformando-se no principal exercício de cultivo social do espírito humano, ela o impede, por um lado, de perambular no vazio, isoladamente, e também, por outro, de se atolar na simples experiência sensorial. Contudo, o papel formativo da disciplina ganha concretude quando se refere à matéria do ensino, considerando simultaneamente tanto o movimento das coisas como os próprios interesses do aluno. Isso significa, então, que os métodos de ensino precisam ser definidos de acordo com os materiais a serem utilizados e as condições físicas e intelectuais que o próprio aluno possui para utilizar tais materiais. Se o aluno consegue perceber que tanto a significação como o manuseio que são dados a tais materiais estão ao seu alcance, a matéria de ensino se torna interessante para ele.

Contudo, a disciplina tem papel formativo também em relação à vontade humana, sendo que nisso se especifica o aspecto eminentemente moral da teoria da instrução de Dewey. Para melhor compreender esse aspecto nuclear de sua ideia de educação, é preciso considerar que o pedagogo americano coloca entre o interesse e a disciplina a vontade (will), definindo-a, de maneira geral, como determinação humana para se alcançar aquilo que se quer. Nesse contexto, não é a vontade débil, mas a vontade forte que põe o ser humano a caminho do fim pretendido. Vontade forte consiste na capacidade executiva da ação, marcada pela energia e pela persistência na realização de aspirações. Desse modo, a capacidade executiva do espírito é crucial à formação da vontade humana, pois quem não aprende a dominar sua vontade não consegue executar seu próprio plano de ação. O autogoverno pedagógico tem primeiramente este sentido, por assim dizer, pragmático imediato de preparar o ser humano para dar conta do que está à sua frente. Preocupado com essa questão e com seu alcance educacional, Dewey define o ser humano com espírito executivo da seguinte maneira: "É aquele que examina seus fins, que torna suas ideias a respeito do resultado de suas ações tão claras e plenas quanto possível" (DEWEY, 2008, p. 140, tradução nossa). Assim, colocar permanentemente sob exame seus propósitos, deixando-se orientar por ideias claras, é a principal característica do espírito executivo. O que o embasa é a capacidade humana de determinação da vontade. 
Qual é a dimensão pedagógica da vontade e que papel a disciplina desempenha em relação a ela? Como móbil da ação, a vontade humana torna-se decisiva para a realização humana na medida em que, orientada por interesses, persegue fins determinados, postos e permanentemente refeitos pela experiência. Como não nasce pronta e como não possui autonomia absoluta em relação ao ambiente, a vontade precisa ser educada, inclusive para poder compreender sua própria autonomia relativa. No contexto da teoria deweyana da instrução, se sua meta é a vida social democrática, trata-se obviamente da formação cooperativa, e, portanto, a formação democrática da vontade torna-se sua questão central. Desse modo, tanto interesse como disciplina são pensados por Dewey na perspectiva do autogoverno pedagógico, visando à formação democrática da vontade humana. ${ }^{21}$

Dewey vê a disciplina, bem nos termos postos pela tradição pedagógica passada, especialmente de acordo com a tradição kantiano-herbartiana, como principal exercício de determinação da vontade. Se o problema é a formação da vontade forte que tenha capacidade executiva, persistente e enérgica, a disciplina desempenha papel importante. Como afirma o pedagogo americano: "uma pessoa preparada para considerar suas ações e para empreendê-las deliberadamente está por isso muito disciplinada" (DEWEY, 2008, p. 140, tradução nossa). O preparo exige a capacidade de persistir no plano de ação inteligentemente escolhido, evitando distrações e falta de foco, que são a origem de muitas outras confusões, próprias a uma vontade fraca.

Nesse contexto, instruction como preparação tem a ver, então, com o fortalecimento da vontade, para que não se deixe abater facilmente pelo que encontra no caminho, mas consiga prosseguir firmemente na busca de fins determinados. Por isso, o sentido de disciplina como formação da vontade democrática está muito distante do sentido autoritário de disciplina, que é imposto de fora. Obviamente que não se trata de "adestrar" comportamentos e, menos ainda, de impor verticalmente interesses que sejam completamente alheios à vontade do sujeito educacional. Formação da vontade democrática exige levar em conta os interesses tanto do professor como do aluno e colocá-los na direção do ensino formativo. Em síntese, a instrução só se torna realmente formativa quando os interesses dos envolvidos são levados em conta e devidamente orientados pela disciplina, visando ao autogoverno de todos os envolvidos no processo pedagógico. 


\section{Considerações finais}

Para concluir, espero ter deixado claro, neste ensaio, o quanto a teoria educacional de Dewey é tributária da tradição, principalmente da moderna tradição da Bildung, e o quanto ela, pela força filosófico-educacional do pensamento de seu autor, que consegue compreender bem os ares dos novos tempos, reatualiza esta mesma tradição, indo muito além dela. Do longo percurso que empreendi, gostaria apenas de reter a noção dinâmica e interativa do espírito, que, alicerçado na condição social, ativa e participante do próprio ser humano, está na base do ideal democrático de vida. É a noção de espírito socialmente ativo e participante que possibilita a Dewey compreender sua teoria da educação como teoria da instrução, ou seja, como preparação para o enfrentamento das adversidades que o mundo socionatural lhe impõe. Contudo, como a instrução humana é eivada de sociabilidade moral, ela prepara o ser humano para modos cultivados de vida. Nesse sentido, tanto interesse como disciplina são exercícios de preparação do ser humano para que este supere formas autoritárias de vida e volte-se para experiências solidárias e cooperativas.

Passados mais de cem anos de publicação da obra Democracy and Education, vê-se o quanto ela permanece atual e o quanto continua nos instruindo contra o crescimento assustador do autoritarismo social e político. Pois somente um espírito bem armado pela cultura democrática refinada eticamente é capaz de resistir às seduções (imposições) neoconservadoras que empobrecem significativamente a experiência humana, na medida em que tomam conta da sociedade atual.

\section{Notas}

1 Para os interessados, este é o endereço de meu blog: <www.rdplanalto/colunistas/claudiodalbosco>.

2 Minha posição diferencia-se neste ponto, em certa medida, da interpretação empreendida por Jürgen Oelkers, no ensaio que consta neste volume da Espaço Pedagógico: enquanto Oelkers se atém exclusivamente em marcar a nítida distância que Dewey toma em relação à tradição pedagógica clássica, eu me ocupo, além disso, em mostrar o vínculo que o pedagogo americano mantém com tal tradição, especialmente no que se refere a Johann F. Herbart.

3 O referido projeto é financiado pelo CNPq na modalidade Bolsa de Produtividade em Pesquisa (PQ).

4 A influência da tradição alemã da Bildung é tão forte no pensamento pedagógico de Dewey que o leva a pensar, como mostra acertadamente Gert Biesta, em ensaio publicado neste volume da Espaço Pedagógico, o nexo estreito entre educação e democracia também na perspectiva moral e não exclusivamente política. Ou seja, pela influência da tradição da Bildung, a democracia, para Dewey, só pode tornar-se referência política na medida em que for tomada antes como ideal moral.

5 Obviamente que o emprego kantiano prático e estético da razão pura implicaria discutir também as noções de ânimo (Gemüt) e razão (Vernunft). No modo como o problema é introduzido nas teorias educacionais e recebido por John Dewey, como problema de fundo da teoria idealista da educação, a noção kantiana de razão equivale à própria noção de espírito.

6 É sintomático, nesse contexto, que, na Alemanha, uma das melhores coletâneas sobre filosofia da mente, organizada por Peter Bieri (1997), não inclua o nome de John Dewey. 
7 Sobre o problema da constituição linguística do Self em Georg Herbert Mead, ver Dalbosco (2010, p. 27-48; 2014, p. 251-262).

8 Para o tratamento do sentido da ação simbólica de Mead no contexto da formação escolar, ver Gert Biesta (2005, p. 139-158).

9 Em seu livro John Dewey und die Pädagogik (John Dewey e a Pedagogia) (2009), cuja primeira edição é de 2000, Jürgen Oelkers inova a recepção do pensamento do pedagogo americano não só no cenário alemão, mas também em relação às pesquisas mundiais atuais (OELKERS, 2010).

10 Tratarei do tema do observador distante na sequência, neste mesmo ensaio.

${ }^{11}$ A noção de condição humana na tradição pragmatista bem como seu vínculo simultâneo com a teoria da ação e a teoria da educação estão ainda por ser amplamente investigados no Brasil. Na Alemanha, por exemplo, o trabalho organizado por Oelkers e Tröhler (2005) dá passos firmes nesta direção. Hans Joas também tem contribuído muito para a compreensão da teoria pragmatista da ação e seu vínculo com a educação e a democracia. Sobre isso, ver a coletânea Philosophie der Demokratie, organizada pelo próprio Hans Joas (2000). Cabe destaque especial, nesta coletânea, para o ensaio de Oelkers (2000, p. 280-315).

${ }^{12}$ É importante notar que a tradução alemã de Democracy and Education traduz a expressão Mind como Geist (DEWEY, 2010, p. 176), termo equivalente ao adotado nesta passagem.

${ }^{13}$ É este precisamente o ponto nuclear que leva Dewey, segundo Jürgen Oelkers, no ensaio que integra este volume da Espaço Pedagógico, a romper com o pensamento educacional clássico.

${ }^{14}$ Dewey trata da simpatia inteligente, colocando-a na base da vontade boa (good will), no capítulo IX de Democracy and Education. Ocupo-me deste problema, juntamente com meu orientando de doutorado, Miguel Rossetto da Silva, em um ensaio, sob o título provisório "John Dewey como leitor de Jean-Jacques Rousseau: o problema da formação das capacidades humanas”, ainda em preparação.

${ }^{15}$ Cabe mencionar também o quanto Dewey deixa-se influenciar por Émile, de Jean-Jacques Rousseau (1999), especialmente pela ideia de condição humana perfectível, dedicando o capítulo IX de Democracy and Education para dialogar criticamente com o pensamento pedagógico do genebrino. No meu último livro sobre Rousseau, dedico atenção especial à perfectibilité como noção pedagógica chave da teoria educacional de Rousseau (DALBOSCO, 2016, p. 110-137).

${ }^{16}$ As pesquisas internacionais atuais sobre a relação entre Herbart e Dewey estão muito avançadas. Para um olhar de conjunto, ver a coletânea organizada por Klaus Prange (2014). Para uma investigação sistemática, que confronte as duas teorias educacionais mediante a ótica da educação como transformação, ver o recente e importante livro de Andrea F. English (2013).

${ }^{17}$ Discuto a questão no texto "Possui a disciplina papel formativo? Um ponto controverso das teorias educacionais", ainda inédito.

${ }^{18}$ Para uma interpretação da noção de interesse em Dewey, voltando-se especificamente para o problema do ensino de filosofia, ver Mendonça, Tortelle e Silva (2013).

${ }^{19}$ Refiro-me ao texto "Possui a disciplina papel formativo? Um ponto controverso das teorias educacionais", ainda inédito.

${ }^{20}$ Para o papel da disciplina nas ideias pedagógicas de Immanuel Kant, ver Dalbosco (2004).

${ }^{21} \mathrm{O}$ problema da formação democrática da vontade humana coloca-se já como grande problema à pedagogia moderna, especialmente para Jean-Jacques Rousseau. Tratei deste tema em meu último livro sobre Rousseau, já referido neste ensaio (DALBOSCO, 2016, p. 248-266).

\section{Referências}

BENNER, D. Die Pädagogik Herbarts. Eine problemgeschichtliche Einführung in die Systematik neuzeitlicher Pädagogik. Weinheim, München: Juventa Verlag, 1993.

BIERI, P. (Hrgs.). Analitische Philosophie des Geites. Weinheim: Beltz, 1997.

BIESTA, G. Georg Herbert Mead und die Theorie der schulischen Bildung. In: OELKERS, J.; TRÖHLER, D. (Org.). Pragmatismus und Pädagogik. Zurique: Verlag Pestalozzianum, 2005. p. 139-158. 
DALBOSCO, C. A. Vom disziplinierten Zwang zur moralischen Verbindlichkeit. Zur Bedeutung der Rolle der Pädagogik bei Kant. Pädagogische Rundschau, Frankfurt am Main, 58. Jahrgang, p. 357-384, 2004.

Pragmatismo, teoria crítica e educação. Ação pedagógica como mediação de significados. Campinas: Autores Associados, 2010.

Die sprachlische Konstitution des Selbst (Self) und die pädagogische Handlung. Pädagogische Rundschau, Jahrgang, v. 68, p. 251-262, 2014.

Condição humana e educação do amor próprio em Jean-Jacques Rousseau. São Paulo: Edições Loyola, 2016.

Condição humana e educabilidade: um problema nuclear das teorias educacionais clássicas. Revista Brasileira de História da Educação, 2017. No prelo.

DEWEY, John. Democracy and Education. The Middle Works, 1899-1924, v. 9. Illinois: Southern Illinois University Press, 2008.

Demokratie und Erziehung. Eine Einleitung in die philosophische Pädagogik. Aus dem Amerikanischen von Erich Hylla. Herausgegeben und mit einem Nachwort von Jürgen Oelkers. Weinnheim/Basel: Beltz, 2010.

ENGLISH, A. Discontinuity in Learning. Dewey, Herbart, and Education as Transformation. New York: Cambridge University Press, 2013.

HERBART, J. F. Pädagogische Schriften. Zweiter Band: Allgemeine Pädagogik, aus dem Zweck der Erziehung abgeleitet (1806). Herausgegeben von Walter Asmus. Düsseldorf/München: Verlag Helmut Küpper Vormals Georg Bondi, 1965. benkian, 2003.

JOAS, Hans (Org.). Philosophie der Demokratie. Beiträge zum Werk von John Dewey. Frankfurt am Main: Suhrkamp, 2000.

MENDONÇA, S.; TORTELLE, J. C. B.; SILVA, A. Q. Interesse e superação do lernification para a prática filosófica. Linhas Críticas, Brasília, DF, v. 17, n. 40, p. 595-608, 2013.

OELKERS, Jürgen. John Dewey's Philosophie der Erziehung: eine theoriegeschichtliche Analyse. In: JOAS, Hans (Org.). Philosophie der Demokratie. Beiträge zum Werk von John Dewey. Frankfurt am Main: Suhrkamp, 2000. . John Dewey und die Pädagogik. Weinheim und Basel: Belz Verlag, 2009.

Dewey in Deutschland. Ein Missverständnis. In: DEWEY, J. Demokratie und Erziehung. Eine Einleitung in die philosophische Pädagogik. Aus dem Amerikanischen von Erich Hylla. Herausgegeben und mit einem Nachwort von Jürgen Oelkers. Weinnheim, Basel: Beltz, 2010. p. 409-509.

OELKERS, J.; TRÖHLER, D. (Org.). Pragmatismus und Pädagogik. Zurique: Verlag Pestalozzianum, 2005.

PRANGE, K. (Org.). Herbart und Dewey. Pädagogische Paradigmen im Vergleich. Jena: Garamond Verlag (Edition Paideia), 2014.

ROUSSEAU, J. J. Émile. Paris: Gallimard, Bibliothèque de la Plêiade, 1999. (Obras Completas, tomo IV). 